\title{
ResearchOnline@JCU
}

This is the Accepted Version of a paper published in the Journal: Brain, Behaviour and Immunity

Mifsud, Karen R., Gutirrèz-Mecinas, María, Trollope, Alexandra F., Collins, Andrew, Saunderson, Emily A., and Reul, Johannes M.H.M. (2011) Epigenetic mechanisms in stress and adaptation. Brain, Behavior, and Immunity, 25 (7). pp. 1305-1315.

http://dx.doi.org/10.1016/j.bbi.2011.06.005

(C) 2015. This manuscript version is made available under the CC-BY-NC-ND 4.0 license http://creativecommons.org/licenses/by-nc-nd/4.0/

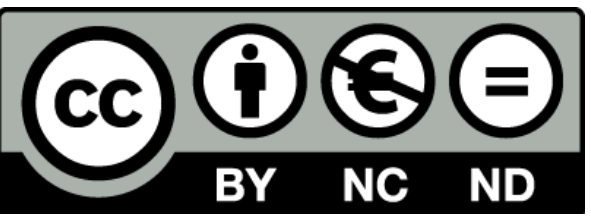


Elsevier Editorial System(tm) for Brain, Behavior, and Immunity Manuscript Draft

Manuscript Number: BBI-D-11-00104R1

Title: Epigenetic mechanisms in stress and adaptation

Article Type: Named Series: Epigenetics

Section/Category: Neurosciences

Keywords: Stress; adaptation; epigenetic; learning; memory; DNA methylation; histone modification; ERK; MAPK; NMDA; glucocorticoid; c-Fos; Egr-1; immune; inflammation; cytokine; hippocampus; dentate gyrus; HPA axis

Corresponding Author: Professor Johannes M.H.M. Reul,

Corresponding Author's Institution: University of Bristol

First Author: Karen R Mifsud

Order of Authors: Karen R Mifsud; Maria Gutierrez-Mecinas; Alexandra F Trollope; Andrew Collins; Emily A Saunderson; Johannes M.H.M. Reul

Manuscript Region of Origin: UNITED KINGDOM

Abstract: Epigenetic mechanisms are processes at the level of the chromatin that control the expression of genes but their role in neuro-immuno-endocrine communication is poorly understood. This review focuses on epigenetic modifications induced by a range of stressors, both physical and psychological, and examines how these variations can affect the biological activity of cells. It is clear that epigenetic modifications are critical in explaining how environmental factors, which have no effect on the DNA sequence, can have such profound, long-lasting influences on both physiology and behavior. A signaling pathway involving activation of MEK-ERK1/2, MSK1, and Elk-1 signaling molecules has been identified in the hippocampus which results in the phospho-acetylation of histone H3 and modification of gene expression including up-regulation of immediate early genes such as cFos. This pathway can be induced by a range of challenging experiences including forced swimming, Morris water maze learning, fear conditioning and exposure to the radial maze. Glucocorticoid (GC) hormones, released as part of the stress response and acting via glucocorticoid receptors (GRs), enhance signaling through the ERK1/2/MSK1-Elk-1 pathway and thereby increase the impact on epigenetic and gene expression mechanisms. The role of synergetic interactions between these pathways in adaptive responses to stress and learning and memory paradigms is discussed, in addition we speculate on their potential role in immune function. 
Review article for Named Series Epigenetics in Brain, Behavior and Immunity

BBI-D-11-00104 Revised

\section{Epigenetic mechanisms in stress and adaptation}

Karen R. Mifsud, María Gutièrrez-Mecinas, Alexandra F. Trollope, Andrew Collins, Emily A. Saunderson and Johannes M.H.M. Reul*

Henry Wellcome Laboratories for Integrative Neuroscience and Endocrinology, University of Bristol, Dorothy Hodgkin Building, Whitson Street, Bristol, BS1 3NY, United Kingdom

*Corresponding author.

Professor Johannes M.H.M. Reul

Tel: +44 1173313137

E-mail: Hans.Reul@bristol.ac.uk

The authors declare that there are no conflicts of interest.

Word count: (excluding references, tables and figures): 7067

Figures: 2

Tables: 1

References: 112 


\title{
Review: Epigenetic mechanisms in stress and adaptation
}

\begin{abstract}
$\underline{\text { Abstract }}$
Epigenetic mechanisms are processes at the level of the chromatin that control the expression of genes but their role in neuro-immuno-endocrine communication is poorly understood. This review focuses on epigenetic modifications induced by a range of stressors, both physical and psychological, and examines how these variations can affect the biological activity of cells. It is clear that epigenetic modifications are critical in explaining how environmental factors, which have no effect on the DNA sequence, can have such profound, long-lasting influences on both physiology and behavior. A signaling pathway involving activation of MEKERK1/2, MSK1, and Elk-1 signaling molecules has been identified in the hippocampus which results in the phospho-acetylation of histone $\mathrm{H} 3$ and modification of gene expression including up-regulation of immediate early genes such as c-Fos. This pathway can be induced by a range of challenging experiences including forced swimming, Morris water maze learning, fear conditioning and exposure to the radial maze. Glucocorticoid (GC) hormones, released as part of the stress response and acting via glucocorticoid receptors (GRs), enhance signaling through the ERK1/2/MSK1-Elk-1 pathway and thereby increase the impact on epigenetic and gene expression mechanisms. The role of synergetic interactions between these pathways in adaptive responses to stress and learning and memory paradigms is discussed, in addition we speculate on their potential role in immune function.
\end{abstract}




\section{Introduction to stress}

The nervous, endocrine and immune systems engage in intense communication throughout the mammalian physiological system via neuronal, hormonal and immunological networks respectively. These systems are widely integrated with each other and allow the organism to adapt to environmental changes and challenges. Stress has been defined as 'a threat, real or implied, to the maintenance of a narrow range of vital homeostatic parameters necessary for survival' (McEwen, 2000). Stress induces a number of biological responses which enables the organism to adapt to the challenge and increase its likelihood of survival. Immediate activation of the sympathetic nervous system releases adrenaline from stores in the adrenal medulla, preparing the organism for a fight or flight response. In addition, stress increases levels of neurotransmitters such as serotonin (5-HT) and noradrenaline (NA) in specific brain regions (i.e. hypothalamus, hippocampus) (Linthorst et al., 1995a; 1996; Linthorst et al., 2002). 5-HT and NA act at the hypothalamus to activate the hypothalamic-pituitary-adrenal (HPA) axis resulting in the release of GCs from the adrenal cortex into the circulation (Carrasco and Van de Kar, 2003). It is hypothesised that the rise in extracellular 5-HT in the hippocampus supports the animal's risk assessment of the nature of the stressor so it can make appropriate adaptations (Linthorst and Reul, 2008).

\section{Animal models for investigating the effects of acute stress}

Researchers investigating the effects of stress in vivo have developed a number of behavioral tests designed to model neuropsychiatric disorders, for review see Nestler and Hyman (2010). In many stress studies animals are exposed to stressors for a limited amount of time and subsequent changes in physiology and behavior determined. Stressors are generally described as either physical or psychological but in reality most stressors present both types of stress and therefore their 'classification' is based on which biological system (physical or 
psychological) is affected the most. Physical stressors, such as a hot or cold environment, have a direct effect on the body, disturbing homeostatic processes and influencing the physiological state of an organism. In contrast, psychological stressors involve higher brain areas, such as the neocortex, amygdala and hippocampus, to process and/or interpret information about the threat. Consequently, in case of psychological stress, the threat may be implied but not necessarily experienced (Herman, 2003).

Both physical and psychological stress activate the HPA axis leading to downstream adrenocorticotropic hormone (ACTH) release from the anterior pituitary and subsequent release of GCs (cortisol in humans, corticosterone in rodents) from the adrenal cortex into the circulation. GCs were so named after their effects on glucose metabolism were discovered. Circulating GCs, however, have equally important roles in modulating the immune response and in cognitive processes such as memory formation (see next section). Despite both physical and psychological stressors activating the same central HPA pathway, a number of studies have provided evidence that the body responds to the different types of stress in distinct ways (Dayas et al., 2001; Yuen et al., 2009). Furthermore, because of its nature, psychologically stressful events lead to profound, long-term changes in behavior.

\section{Role of memory formation in the stress response}

Memory formation is the storage of information which can be recalled in the future. The processes involved in the formation of memories have been the focus of numerous studies spanning over 30 years but a definitive pathway is still being elucidated. Biochemical pathways leading to memory formation can be examined through the use of behavioral tests such as the Morris water maze, Pavlovian fear conditioning, radial maze and others - a summary of the most common behavioral tests for stress/learning and memory studies are outlined in Table 1. All of these tests have a 'stressful' component which must be taken into 
account when interpreting experimental findings. Indeed in recent years there has been considerable overlap between investigations into stress responses and learning and memory processes, with signaling pathways emerging that are common to both areas. Long term responses to stress include the formation of episodic memories which increase the chance of avoiding the stressful challenge in the future or improve the ability of the organism to cope with any subsequent repeat exposure to the stressor (Reul and Chandramohan, 2007; Reul et al., 2009) This is, in part, due to the strong consolidation of memories by the induction of stress hormones such as GCs, however, the exact mechanism for this consolidation remains unclear (Oitzl and de Kloet, 1992; Cordero and Sandi, 1998; De Quervain et al., 2009; Sandi, 2011).

\section{$\underline{\text { Epigenetics }}$}

As discussed in the first review of this series (Mathews and Janusek, 2011), epigenetic modifications change the expression of genes without altering the DNA sequence. These modifications can occur on the DNA itself to influence gene expression by changing the accessibility of genes to transcription/translation factors. Alternatively, other distinct epigenetic modifications can occur on the highly conserved tails of histone proteins, responsible for organizing DNA into chromatin, thereby affecting chromatin assembly and organization of DNA.

According to the National Institute of Health, epigenetic changes can be 'heritable changes in gene activity and expression (in the progeny of cells or of individuals) and also stable, longterm alterations in the transcriptional potential of a cell that are not necessarily heritable'. The latter aspect explains how environmental influences and life experiences can result in differences in gene expression and downstream biological changes, even after the initial 


\section{DNA modifications}

DNA methylation occurs when a methyl group is added to one of the pyrimidine bases of DNA. Methylation occurs on the $5^{\text {th }}$ carbon of cytosine residues $(5 \mathrm{mC})$ situated adjacent to a guanine residue ( $\mathrm{CpG}$ site). Parts of DNA sequences with a high concentration of $\mathrm{CpG}$ residues are referred to as $\mathrm{CpG}$ 'islands' and generally located at the start of the gene sequence within the promoter region. The methylation of DNA within the promoter region of a gene may be why this modification has such a profound effect on gene expression, generally silencing the expression of the respective gene (Illingworth and Bird, 2009).

DNA methylation can occur by two type of enzymes; methyl-transferases de novo, which setup methylation marks during early development and are critical for the survival of organisms, and maintenance methyl-transferases which are essential for maintaining the methylation code (Wu and Zhang, 2010). The importance of demethylation has been investigated to a greater extent in recent years as it has become apparent that DNA methylation status can change quite rapidly (Wu and Zhang, 2010). The exact biochemical processes involved in DNA demethylation remains unclear but there are a number of mechanisms currently being discussed including enzymatic removal, deamination and base excision repair, nucleotide excision repair, oxidative demethylation and radical S-adenosylmethionine (SAM)-based demethylation (for review see Wu and Zhang (2010)). 
In addition to methylation and demethylation, mammalian DNA can by hydroxylated (oxidation of $\mathrm{CH}$ group to form $\mathrm{COH}$ ) at the carbon 5 position of methylated cytosine residues (Penn et al., 1972) but the induction and function of this hydroxy-methylation (5hmC) modification is unknown. More recent studies (Tahiliani et al., 2009; Zhang et al., 2010) have identified 5-methylcytosine $(5 \mathrm{mC})$ hydroxylases like ten-eleven translocation proteins (TET1, TET2 and TET3) as enzymes responsible for hydroxylation of methylcytosine but the function of this mark still remains unclear. It has been proposed that 5hmC facilitates passive demethylation (promoting gene transcription) by preventing DNMT's maintaining the methylation status of DNA, however, this is yet to be confirmed (Tahiliani et al., 2009). Hydroxy-methylation of DNA recruits 5hmC-specific factors and prevent the association of some $5 \mathrm{mC}$-specific enzymes/transcription factors in DNA methylation assays and cancer cell lines, indicating distinct roles for the two types of cytosine modification in gene expression (Valinluck and Sowers, 2007; Tahiliani et al., 2009; Ko et al., 2010).

\section{Histone modifications}

Histone proteins are responsible for organizing DNA into chromatin which can exist in a densely-packed 'closed' configuration or in a loose, 'open' state, which is required for gene transcription. There are four core histone proteins, $\mathrm{H} 2 \mathrm{~A}, \mathrm{H} 2 \mathrm{~B}, \mathrm{H} 3$ and $\mathrm{H} 4$, each with a highly conserved N-terminal tail which can be modified at certain sites by a range of specific enzymes to influence the structure and function of the chromatin.

Histone methylation occurs on either arginine or lysine residues in histones H3 and H4. The enzymes which add (methyl-transferases) or remove (demethylases) methyl groups are specific to the residue on which they act, either lysine or arginine, and can also be specific for 
the location or site of the residue within the histone tails. For example, mixed lineage leukemia proteins (MLLs) are methyl-transferases which act almost exclusively to methylate lysine residue 4 of histone $\mathrm{H} 3$ (Cosgrove and Patel, 2010). The function of the methylation mark depends on the site on which it occurs; lysine methylation of H3K4 (lysine 4 of histone 3) is associated with transcriptionally active chromatin and gene transcription whereas methylation on H3K9 is associated with gene silencing (Kouzarides, 2007; Akbarian and Huang, 2009). The consequence of methylation is also dependant on how many methyl groups are added to each residue; lysine residues hold one, two or three methyl groups and are classified as mono, di or trimethylated respectively, whereas arginine residues can only hold up to two methyl groups (Kouzarides, 2007). The function of methylated H3K20 varies greatly with methylation status, mono-, di- and trimethylation of this site has been associated with gene transcription, gene repair and gene silencing respectively (Balakrishnan and Milavetz, 2010). The consequence of epigenetic marks is further complicated by the interaction of different modifications on each other; for example, protein arginine methyltransferase (PRMT) methylation of H3R2 prevents methylation of H3K4 by MLL and therefore inhibits subsequent gene expression in vitro (Hyllus et al., 2007).

Histone phosphorylation occurs when a phosphate group is added to an amino acid residue (usually serine) in the highly conserved histone tail by specific kinases and can be removed by specific phosphatases (dephosphorylation) (Thomson et al., 1999b; 1999a; Clayton et al., 2000; Soloaga et al., 2003). The phosphorylation status of chromatin is determined by the net activity of kinases and phosphatases, influenced by signaling cascades. Phosphorylation of certain residues is often associated with other epigenetic marks, for example if histone $\mathrm{H} 3$ in dentate gyrus neurons is phosphorylated at serine 10 then it is also generally acetylated at lysine 14 (Chandramohan et al., 2007). This co-modification is associated with the opening of 
previously condensed chromatin (Cheung et al., 2000; Clayton et al., 2000; Nowak and Corces, 2000) .

Histone acetylation occurs when an acetyl group $\left(\mathrm{COCH}_{3}\right)$ is added to a lysine residue by histone acetyl-transferases (HATs). Once again these enzymes act at distinct residues/sites within the N-terminal tail of histone proteins. Given the neutralization of the negative lysine charge by the addition of a positively charged acetyl group, histone acetylation is the modification most likely to decondense chromatin and expose previously silent genes for transcription (Kouzarides, 2007). This epigenetic mark is therefore almost exclusively associated with active gene transcription for numerous genes studied. Acetyl groups are removed by histone deacetylases (HDACs).

Some epigenetic marks such as methylation of DNA can be passed on to subsequent generations through mitotic and meiotic cell division (Nakayama et al., 2000; Schreiber and Bernstein, 2002; Champagne, 2008). This is an interesting property which is not shared by alternative mechanisms of altering gene expression (i.e. the influence of transcription factors). Although changes in the epigenetic profile of DNA were traditionally thought to be hereditary, recent studies indicate these changes can be transient ( $\mathrm{Ng}$ et al., 2009). Epigenetic modifications are therefore a set of biochemical tools which control the expression of genes and are themselves controlled by signaling mechanisms and provide another level at which the environment can impact on gene expression (Figure 1).

\section{Role of epigenetic mechanisms in the long-term impact of early life stress}

The epigenetic profile of rats is profoundly influenced by the maternal behavior they experienced during the first week of life (Weaver et al., 2004). Rats which received high 
levels of maternal care (HMC rats, maternal care defined as licking, grooming and archedback nursing) during the first week of life were less anxious, less sensitive to stress in adult life and had higher levels of GR expression in the hippocampus compared with rats experiencing low levels of maternal care as pups (LMC rats).

Analysis of the methylation state of the GR promoter during the development of HMC or LMC pups revealed changes in the methylation status of a specific cytosine residue (site 16 on exon $1_{7}$ ), which corresponded to a specific region in the GR promoter containing a consensus sequence for a transcription factor known as early growth response factor 1 (Egr1). At the embryonic stage site $16 /$ exon $1_{7}$ is unmethylated but DNA methylation of this site occurs shortly after birth. In HMC pups demethylation of site 16/exon $1_{7}$ occurs during the first week of life, whereas this site in LMC rats remains methylated. Since this site contains a consensus sequence for Egr-1, the association of Egr-1 protein with the GR promoter was analysed by chromatin immuno-precipitation assay (ChIP) and found to be 3-fold higher in HMC rats compared with LMC rats. ChIP analysis of GR also found higher levels of acetylation at histone $\mathrm{H} 3$ lysine 9 (H3K9), a marker for uncondensed, transcriptionally active chromatin (Weaver et al., 2004).

Prolonging histone acetylation by intracerebroventricular (i.c.v) administration of histone deacetylase (HDAC) inhibitor trichostatin A (TSA) in LMC rats supported a role for histone acetylation in the response by promoting a phenotype closely associated with that of HMC rats (Weaver et al., 2004). Likewise, when Egr-1 binding to the GR promoter was inhibited by DNA methylation at site 16/exon $1_{7}$ the HMC phenotype (less anxious, less sensitive to stress and higher GR expression in hippocampus) disappeared indicating a key role for demethylation of DNA in this phenotype (Weaver et al., 2004). Later studies found that the 
level of maternal care experienced when pups by female rats determined what kind of mother they would themselves become as a consequence of epigenomic changes in a different gene, namely the estrogen receptor gene located in the medial preoptic area, highlighting the transgenerational effects of epigenetic modifications (Champagne, 2008). Generally it appears that HMC rats become HMC mothers and LMC rats become LMC mothers (Champagne, 2008).

A link has also been demonstrated between early life experiences and adult behavior in humans. Numerous clinical studies have shown a positive association between childhood trauma and increased risk of developing psychopathological disorders such as depression as an adult (Heim et al., 2008). Children experiencing abuse, neglect or other adverse experiences displayed a sensitized stress response, GC resistance, increased corticotropinreleasing factor (CRF) activity, immune activation and reduced hippocampal volume; all features which have been observed in some depressed patients as adults (Heim et al., 2008). Reduced GR mRNA expression in the hippocampus of suicide victims who had been abused as children was associated with epigenetic changes in the neuron-specific GR promoter (NR3C1) when compared with suicide victims with no history of childhood abuse (McGowan et al., 2009). There were also higher levels of DNA methylation in the hippocampal GR promoter in abuse victims compared with non-abuse controls; this pattern of methylation resulted in reduced binding of transcription factor Egr1 and decreased levels of Egr1-induced gene transcription when investigated in vitro (McGowan et al., 2009). Based on these studies, epigenetic modifications play a key role in mediating the effect of early life experiences on responses to stress in adulthood. 


\section{Epigenetics: stress studies and signaling pathways}

Our recent studies have investigated the effect of acute stressors on epigenetic modifications in brains of adult rats. The primary stressor used in our studies is the forced swim test and we are particularly interested in the subsequent immobility response displayed by the rats in the forced swim retest ( $24 \mathrm{~h}$ after initial test). There is controversy surrounding the interpretation of the animal's immobility response. Originally the immobility response was viewed as a 'depressive' behavior because it was thought that the animal had given up and showed despair (Porsolt et al., 1977; Lucki, 1997). In addition, the effects of some antidepressant drugs to lower the immobility response seemed to support this notion. On the other hand, acute administration of many antidepressants evokes arousal through central release of serotonin, noradrenaline and/dopamine which may provide an alternative explanation for the reduced immobility behavior. Furthermore, the effect of three administrations of antidepressant drug in the Porsolt forced swim test design is hard to reconcile with the clinical effects of antidepressants which take at least 3 weeks of treatment to emerge. Our group and others feel that the immobility response is an adaptive response to the knowledge that they cannot escape making it more appropriate to conserve energy to maximize the chance of survival (De Pablo et al., 1989; West, 1990; Korte, 2001; Bilang-Bleuel et al., 2005; Nestler and Hyman, 2010). The rapid adoption of immobility behavior in the retest supports the idea that the subject remembers the initial test and conserves its energy by floating. Further support of immobility being an adaptive response comes from forcing the rats to swim in water at different temperatures. Normally the rats are swum at $25^{\circ} \mathrm{C}$, however, when rats are swam at $19^{\circ} \mathrm{C}$ rats they show increased struggling and reduced immobility during the retest, possibly because of the extreme loss of body temperature $\left(\sim 12^{\circ} \mathrm{C}\right)$. In contrast, rats that swam at $35^{\circ} \mathrm{C}$ showed high levels of immobility and very little struggling (Linthorst et al., 2008). This experiment underscores the immobility behavior being an 
Immunofluorescent staining confirmed epigenetic modifications were taking place in distinct brain areas with positive staining for phosphorylation of serine 10 and acetylation of lysine 14 in histone $\mathrm{H} 3$. Under baseline conditions very low levels of $\mathrm{H} 3$ phospho-acetylation were found in the dentate gyrus, neocortex, amygdala and striatum (Bilang-Bleuel et al., 2005; Chandramohan et al., 2007). On exposure to forced swim stress there was a marked increase in phospho-acetylation of histone $\mathrm{H} 3$, specifically in the dentate gyrus, which did not occur after exposure to purely physical stresses such as cold environment and ether exposure. This finding indicates that the psychological component of the stress may be responsible for the observed increase in $\mathrm{H} 3$ phospho-acetylation (Bilang-Bleuel et al., 2005).

N-methyl-D-apartate (NMDA) receptor blockade, using receptor antagonist MK-801, prevented the forced swim induced increase in H3S10p-K14ac positive neurons in the dentate gyrus of rats and also reduced the associated immobility behavior in the 1-day retest (Chandramohan et al., 2008). Neurons in the dentate gyrus are under tonic inhibitory control by gamma amino-butyric acid (GABA)-ergic interneurons. FG-7142 ( $\beta$-carboline-3carboxylic acid $\mathrm{N}$-methylamide), a GABA-A receptor partial inverse agonist attenuated the GABAergic control of granule neurons in the dentate gyrus, resulting in a rise in the number of H3S10p-K14ac-positive neurons in this hippocampal structure (Papadopoulos et al., 2010). The proportion of granule neurons in the dentate gyrus that overcome the inhibitory 
regulation is dependent on the strength of the stimulus. Most psychological stressors (predator exposure, novel environment etc.) activate $<5 \%$ of dentate gyrus granular neurons from inhibitory control. In contrast, much stronger stimuli such as electroconvulsive shock or injection of depolarizing drugs can overcome virtually all inhibitory GABAergic control resulting in activation of all dentate granule neurons (Green and Vincent, 1987; Crosio et al., 2003).

Once the inhibitory control is overcome by excitatory inputs (mainly glutamatergic), glutamate binds to NMDA receptors resulting in a rise in intracellular calcium $\left(\mathrm{Ca}^{2+}\right)$ concentration. Increased intracellular $\mathrm{Ca}^{2+}$ levels trigger a number of biochemical signaling cascades including the activation of adenylate cyclase (and subsequent protein kinase A (PKA) activation), $\mathrm{Ca}^{2+}$-calmodulin kinase II (CAMKII) and the mitogen-activated protein kinase (MAPK) cascade leading to activation of the extracellular-regulated protein kinases 1 and 2 (ERK1/2). Inhibition of ERK1/2 activation, using an inhibitor (i.e. SL-327) of the upstream MAPK ERK kinase (MEK), abolished phospho-acetylation of histone $\mathrm{H} 3$ and the subsequent immobility response in response to forced swim stress (Chandramohan et al., 2008). ERK1/2 targets a number of downstream kinases including mitogen and stressactivated kinases 1 and 2 (MSK1/2). MSK1/2 double knock-out mice subjected to the same forced swim protocol (although initial test was for $10 \mathrm{~min}$ as opposed to $15 \mathrm{~min}$ ) showed no increase in phospho-acetylation of histone $\mathrm{H} 3$ and the immobility response was also blocked compared with control mice (Chandramohan et al., 2008). This study shows that blocking ERK1/2 and MSK signaling prevents forced swim induced epigenetic changes and subsequent immobility behavior during the retest, indicating a key role for these signaling molecules in the adaptive behavioral response to stress. 
Once activated, MSK can phosphorylate residues on histone tails including S10 which may explain its critical role in inducing epigenetic modifications (Figure 2), however, MSK has no known acetylase activity (Hauge and Frödin, 2006; Arthur, 2008; Drobic et al., 2010). MSK can also phosphorylate cAMP responsive element (CRE) binding protein (CREB) which after dimerization can bind to CRE sites in the promoters of many cAMP- and $\mathrm{Ca}^{2+}$-responsive genes thereby stimulating gene expression (Figure 2). Furthermore, CREB can recruit a number of histone modifying enzymes to the chromatin including p300 and/or CREB binding protein (CBP), both of which have histone acetyl-transferase (HAT) activity and have been shown to potentiate long term memory formation (Vecsey et al., 2007). Despite the promising role of CREB in promoting stress-induced epigenetic modifications, investigations into its activation in response to forced swim stress revealed widespread activation throughout the dentate gyrus, the rest of the hippocampus and many other brain areas (Bilang-Bleuel et al., 2002). The widespread phosphorylation of CREB in dentate gyrus neurons after psychological challenges such as forced swimming presents a conundrum which will be addressed further below.

An alternative downstream target of ERK activation is E twenty-six (ETS)-domain protein (Elk-1), a transcription factor which can bind to Elk binding sites in serum response elements of gene promoters and recruit HATs such as p300 (Li et al., 2003). Immunohistochemical studies identified pElk-1 expression in the same neurons that were positive for H3S10pK14ac, pERK1/2 and pMSK1 confirming a potential role for this signaling molecule in acetylation of H3 (Gutierrez-Mecinas et al., 2009).

Expression of the immediate early gene $c$-fos is commonly used as a marker for neuronal activation as it is often expressed when neurons become activated (Hoffman et al., 1993). c- 
Fos is a transcription factor which acts in conjunction with other proteins to induce

In view of the strong transactivation potential of pCREB regarding c-fos gene transcription (Berkowitz et al., 1989; Boutillier et al., 1992; Herdegen and Leah, 1998), it is obvious that the forced swimming-induced sparse induction pattern of c-Fos in dentate granule neurons in the face of a virtually ubiquitous activation of CREB in these neurons is a striking conundrum. Basically, the question is why is c-Fos only sparsely induced in dentate neurons when $\mathrm{pCREB}$ is generated in all neurons? Our recent signaling and epigenetic studies may provide an answer to this question. We have shown that the induction of c-Fos in dentate neurons requires the activation of GRs in conjunction with the NMDA/ERK1/2/MSK1-Elk-1 signaling pathway which results in the phosphorylation and acetylation of histone $\mathrm{H} 3$ tails. This combinatorial histone mark is known to be involved in the opening of condensed, inactive chromatin rendering it available for transcription (Cheung et al., 2000; Clayton et al., 2000; Nowak and Corces, 2000). As transcription factors like pCREB require an open 
The hippocampus expresses high levels of GR and is responsible for co-ordination of neuroendocrine and behavioral responses to stress making it a prime site for studies of the stress response in vivo (Reul and de Kloet, 1985; De Kloet and Reul, 1987; De Kloet et al., 2005). In the early 1980s it was observed that the behavioral immobility response, as displayed in the forced swim re-test, is strongly dependent on glucocorticoid hormones secreted during the initial forced swim challenge and acting via GRs (Veldhuis and De Kloet, 1983; Jefferys et al., 1983). Follow-up work demonstrated that specifically GRs in the dentate gyrus are crucial for the forced swimming induced behavioral immobility response (De Kloet et al., 1988). Using the selective receptor antagonists RU38486 and ORG 34517 we examined whether there was a relationship between the histone $\mathrm{H} 3$ phospho-acetylation response and the behavioral immobility response following forced swimming. The forced 
A serendipitous finding emerging from the above studies found a decrease in hyperacetylation of histone $\mathrm{H} 4$, another epigenetic modification, following forced swim stress at multiple locations within the brain (neocortex, hippocampus etc) (Trollope and Reul, unpublished results). In contrast, the stress-induced increase in $\mathrm{H} 3$ phospho-acetylation (H3S10p-K14ac) and c-Fos was specifically located to the dentate gyrus, with the majority of positive neurons situated amongst the mature neurons of the middle and outer aspects of the granular cell layer in the dorsal blade of the dentate gyrus (Bilang-Bleuel et al., 2005; Chandramohan et al., 2007; 2008). Since young, immature neurons of the dentate gyrus are located in the inner aspect of the granular cell layer, close to the subgranular zone, this finding indicates a high degree of neuroanatomical specificity with regard to this molecular 
response to stress and highlights how the accessibility of a gene may vary between cell populations and tissues depending on chromatin conformation.

\section{Epigenetics: role in learning and memory}

Adaptive and coping behaviors such as immobility in the forced swim retest and freezing in the fear conditioning retest are dependent on successful memory formation during initial training/tests. GR activation during the consolidation phase of the forced swim test is required for the normal expression of behavioral immobility in the retest. Studies in learning and memory tests such as contextual fear conditioning and Morris water maze learning have identified a similar dependence on GR at a critical stage in memory consolidation hinting that these tests may all share a central pathway for memory formation (Oitzl and de Kloet, 1992; Cordero and Sandi, 1998; Revest et al., 2005). Histone modification and c-Fos induction have also been shown to occur in response to a number of learning and memory paradigms in vivo (Chwang et al. 2007). In these studies, ERK1/2 inhibition (by the specific MEK inhibitor U0126) and MSK1 knockout mice were used in fear conditioning and Morris water maze tests to identify an ERK1/2-MSK1-H3S10p-K14ac dependent signaling pathway in the mouse hippocampus. This pathway was responsible for the adaptive behavior learnt and displayed in these tests; blocking this pathway blocked the learned behavior (Chwang et al., 2007). This ERK1/2-MSK1-H3S10p-K14ac pathway identified by Chwang et al. (2007) is analogous to the one we identified in response to forced swim and novelty stress indicating that a common pathway is activated by a range of stressful learning paradigms.

Memory formation plays a key role in both stress responses and learning paradigms, and epigenetic modifications are critical in the response to a variety of stressors such as forced swim, Morris water maze and fear conditioning (Chwang et al., 2007; Chandramohan et al., 
2008). Taken together, these observations indicate that epigenetic modifications underlying changes in gene expression may be contributing to the process of memory formation and/or retrieval alongside previously identified modulators of learning and memory processes.

\section{Application of the signaling pathways to the chromatin during immune stress}

The focus of this review has been the role of epigenetic modifications in psychological stress responses and memory formation but there is evidence in the literature of similar pathways playing a role in the epigenetic response to immune stress. This may not be surprising since the immune system is highly integrated with the neuronal and endocrine systems and interacts significantly with key modulators of both systems (Besedovsky and Rey, 2007).

GCs, released after HPA axis activation, modulate the expression of a broad range of cytokines (Wiegers and Reul, 1998). The traditional view is that GCs generally inhibit proinflammatory cytokine expression but in other studies GC release increases the expression of receptors for these proinflammatory cytokines (Wiegers and Reul, 1998; Liberman et al., 2007). This apparent conundrum may be explained if the role of GCs is to 'optimise the course of a biological response' and regulate the balance between pro- and anti-inflammatory cytokine expression (Wiegers and Reul, 1998; Elenkov and Chrousos, 2002). One mechanism by which GCs may optimise the biological response was proposed by Wiegers and Reul (1998). They used the example of T-cell proliferation to demonstrate that the action of GCs to reduce cytokine expression (in this case IL2) is not necessary paralleled by a reduction in biological response. Indeed, the fact that GCs reduced the time of the peak expression of IL2 receptor (IL-2R) by two days actually resulted in a faster, superior biological response compared with the response in the absence of GCs (Wiegers et al., 1995; 2001). This GCinduced optimisation was possible because it is the receptor expression, and not cytokine 
availability, which is the limiting factor in this phase of the response (Wiegers and Reul, 1998). They showed that CD4 levels were increased during GC-induced rises in T-cell proliferation (Wiegers et al., 2000). Furthermore, these GC-induced responses were desensitized if the rats had experienced high circulating GC levels for an extended period of time (Sterzer et al., 2004).

Interleukin 4 (IL-4) is an anti-inflammatory cytokine produced by T-cells which acts in an autocrine manner to elicit a key role in the differentiation of T-cells. GCs regulate the expression of this cytokine indirectly by removing the inhibitory control of IL-4 by IL-12 (Elenkov and Chrousos, 2002). In addition to its role as an anti-inflammatory agent, IL-4 has a neuromodulatory function and its receptor is functionally expressed in the granular neurons of the dentate gyrus in adult rats (Nolan et al., 2005). Preventing IL-4 production by T-cells in meningeal spaces severely impairs performance in behavioral studies targeting learning and memory processes such as the Morris water maze (Derecki et al., 2010). Further investigations found a strong correlation between IL-4 production and upregulation of brainderived neurotrophic factor (BDNF) mRNA and protein in the hippocampus. BDNF is associated with neural plasticity and is an important factor in the consolidation of memories (Schaaf et al., 2000). Since the hippocampus is one of the key sites for memory processing, it was hypothesised that meningeal T cell-derived IL-4 production is enhancing cognitive function via BDNF expression in the hippocampus (Takei et al., 2010). The signaling pathways activated by IL-4 which are responsible for the enhanced performance in learning and memory tasks is unknown, however, since BDNF expression has been accompanied by increased acetylation of histone H3 and H4 (Takei et al., 2010), and since IL-4 can phosphorylate MAPK and induce phospho-acetylation of H3 (H3S10p-K14ac) in T-cells 
(Kraus et al., 2010), a similar, epigenetic based mechanism to that proposed to occur in response to psychological stress (Reul and Chandramohan, 2007) is promising.

\section{$\underline{\text { Role of epigenetics in psychiatric and neurological disorders }}$}

Although epigenetic modifications are beginning to emerge as having a role in a range of diseases this review will focus on just a couple, namely post traumatic stress disorder (PTSD) and multiple sclerosis.

\section{Post traumatic stress disorder (PTSD)}

Since the 1980's, PTSD has been recognised as a pathological anxiety disorder, which can develop after exposure to a traumatic event (Yehuda and Bierer, 2009). Prior to this it was thought that once the threat (stressor) was no longer present the symptomatic effects of stress would disappear. It seems clear now that a certain proportion of victims of trauma (rape, war situations) will develop PTSD-associated symptoms over the course of time, even after the stressful situation or time period has passed. Symptoms associated with PTSD include hyperarousal (alertness, possibly mediated by the release of noradrenaline), avoidance of stressful situations and the recall of traumatic memories (Nair and Singh Ajit, 2008). Physiological changes including a reduction in basal cortisol levels, an increase in corticotrophin releasing hormone $(\mathrm{CRH})$ in cerebral spinal fluid and increased expression of GR in lymphocytes have been found in PTSD patients when compared with matched controls (Yamamoto et al., 2009; Yehuda and Bierer, 2009). Since all these changes are associated with the HPA axis this has lead to the notion that the pathology of PTSD is caused by aberrant function of the HPA axis (Yehuda and Bierer, 2009). PTSD has also been associated with abnormal immune function. Patients with PTSD show high levels of circulating inflammatory markers, lower natural killer cell activity and lower T-lymphocyte counts when 
compared with matched controls (Pace and Heim, 2011). It is unclear whether the changes in immune factors are a result of the aberrant HPA axis or initiate the sensitisation of the HPA axis since IL1 has been shown to elicit long-lasting changes in HPA axis function and vice versa (Schöbitz et al., 1994; Linthorst et al., 1994; 1995b; Labeur et al., 1995; Linthorst et al., 1995a; Reul et al., 1998; Linthorst et al., 1999; Schmidt et al., 2003).

Administration of FG-7142, a partial indirect GABA-A receptor inverse agonist which inhibits GABA function, can induce PTSD-like symptoms in humans whereas exposure to GABA-A agonists like alcohol during a traumatic experience reduce the likelihood of developing PTSD (Kalueff and Nutt, 1996; Evans and Lowry, 2007). These effects may be linked to epigenetic modifications since studies in rats have shown that lorazepam, a benzodiazepine indirect GABA-A receptor agonist, has strong anxiolytic properties and inhibits phospho-acetylation of histone $\mathrm{H} 3$ (H3S10p-K14ac) in response to stress (Papadopoulos et al., 2010). Treatment of rats with FG-7142 has the opposite effect, i.e. the animals show increased anxiety-related behavior and enhanced levels of H3S10p-K14acpositive neurons in the dentate gyrus in response to a novel environment challenge (Reul and Nutt, 2008; Papadopoulos et al., 2010). It is thought that traumatic early life experiences increase the likelihood of developing PTSD in later life. Work of Meaney and colleagues has shown that the DNA methylation status is critical in linking early life experiences with adult responses to stress (Weaver et al., 2004). Demethylation of genes involved in immune function, such as toll-like receptor 1 and 3 (TLR1 \& TLR3), interleukin 8 (IL8), lymphotoxin alpha (LTA) and killer cell lectin-like receptor subfamily G, member 1(KLRG1) have been observed to correlate strongly with the occurrence of PTSD following a traumatic event (Uddin et al., 2010). Exposure to single prolonged stress (SPS, see Table 1) provoked a phenotype in rats similar to PTSD and therefore these rats were used as an animal model of 
PTSD in subsequent studies (Yamamoto et al., 2009). When SPS/PTSD rats were assessed in fear conditioning tests there was increased acetylation of histone $\mathrm{H} 3$ and $\mathrm{H} 4$ in the promoter regions for exon I and IV of the BDNF gene in the hippocampus when compared with fear conditioned control rats (no exposure to SPS). The changes in histone acetylation induced by fear conditioning training in the animal model of PTSD was associated with increased freezing behavior during the subsequent retest (Takei et al., 2010). Taken together these studies indicate an emerging role for epigenetic modifications in the development and prevalence of PTSD.

\section{Multiple sclerosis}

Multiple sclerosis (MS) is a neuroimmunological disease which is characterised by demyelination of neurons in the central nervous system resulting in a number of detrimental symptoms including muscle weakness, cognitive impairment including deficits in memory formation and retrieval, fatigue, mood disorders and many others (Heesen et al., 2007). Studies on MS patients and the MS animal model (experimental autoimmune encephalomyelitis (EAE)) have shown an involvement of the HPA axis in the vulnerability for and progression of this autoimmune disease (Stefferl et al., 1999; 2001; Heesen et al., 2007). Levels of DNA methylation in the promoters of specific genes are lower in patients suffering from MS compared with healthy controls. One of these genes, peptidyl argininedeiminase 2, is overexpressed in MS and promotes the citrullination (conversion of arginine to citrulline) which alters how the protein is folded due to an increase in hydrophobicity causing a pathological phenotype (Mastronardi et al., 2007). Exploratory studies have also shown a surprising role for the histone deacetylase inhibitor TSA as a beneficial treatment for MS suggesting a loss of acetylation marks is also occurring during disease progression (Camelo et al., 2005). 


\section{Acknowledgment}

Our work described in this review article is supported by the Biotechnology and Biological Sciences Research Council (BBSRC; Grant Reference Numbers BB/F000510/1 and $\mathrm{BB} / \mathrm{G} 02507 \mathrm{X} / 1$ ) as well as a Medical Research Council (MRC)-funded In Vivo Neuroscience Capacity Building PhD Studentships (to A.C. and E.A.S.) of the United Kingdom. 


\section{References}

Akbarian S, Huang H-S (2009) Epigenetic regulation in human brain-focus on histone lysine methylation. Biol. Psychiatry 65:198-203

Arthur JSC (2008) MSK activation and physiological roles. Fronti. Biosci. 13:5866-79

Balakrishnan L, Milavetz B (2010) Decoding the histone H4 lysine 20 methylation mark. Crit. Rev. Biochem. Mol. Biol. 45:440-52

Bassett JR, Cairncross KD, King MG (1973) Parameters of novelty, shock predictability and response contigency in corticosterone release in the rat. Physiol. \& Behav. 10:901-7

Berkowitz L a, Riabowol KT, Gilman MZ (1989) Multiple sequence elements of a single functional class are required for cyclic AMP responsiveness of the mouse c-fos promoter. Mol. Cell. Biol. 9:4272-81

Besedovsky HO, Rey AD (2007) Physiology of psychoneuroimmunology: a personal view. Brain, Behav., Immun. 21:34-44

Bilang-Bleuel A, Rech J, De Carli S, Holsboer F, Reul JMHM (2002) Forced swimming evokes a biphasic response in CREB phosphorylation in extrahypothalamic limbic and neocortical brain structures in the rat. Eur. J. Neurosci. 15:1048-60

Bilang-Bleuel A, Ulbricht S, Chandramohan Y, De Carli S, Droste SK, Reul JMHM (2005) Psychological stress increases histone $\mathrm{H} 3$ phosphorylation in adult dentate gyrus granule neurons: involvement in a glucocorticoid receptor-dependent behavioural response. Eur. J. Neurosci. 22:1691-700

Boutillier a L, Barthel F, Roberts JL, Loeffler JP (1992) Beta-adrenergic stimulation of cFOS via protein kinase $A$ is mediated by cAMP regulatory element binding protein (CREB)dependent and tissue-specific CREB-independent mechanisms in corticotrope cells. J. Biol. Chem. 267:23520-6

Camelo S, Iglesias AH, Hwang D, Due B, Ryu H, Smith K, Gray SG, Imitola J, Duran G, Assaf B, Langley B, Khoury SJ, Stephanopoulos G, De Girolami U, Ratan RR, Ferrante RJ, Dangond F (2005) Transcriptional therapy with the histone deacetylase inhibitor trichostatin A ameliorates experimental autoimmune encephalomyelitis. J. Neuroimmunol. 164:10-21

Carrasco GA, Van de Kar LD (2003) Neuroendocrine pharmacology of stress. Eur. J. Pharmacol. 463:235-72

Champagne FA (2008) Epigenetic mechanisms and the transgenerational effects of maternal care. Front. Neuroendocrinol. 29:386-97

Chandramohan Y, Droste SK, Arthur JSC, Reul JMHM (2008) The forced swimminginduced behavioural immobility response involves histone $\mathrm{H} 3$ phospho-acetylation and c-Fos induction in dentate gyrus granule neurons via activation of the N-methyl-D- 
aspartate/extracellular signal-regulated kinase/mitogen- and stress-activated kinase signalling pathway. Eur. J. Neurosci. 27:2701-13

Chandramohan Y, Droste SK, Reul JMHM (2007) Novelty stress induces phosphoacetylation of histone $\mathrm{H} 3$ in rat dentate gyrus granule neurons through coincident signalling via the N-methyl-D-aspartate receptor and the glucocorticoid receptor: relevance for c-fos induction. J. Neurochem. 101:815-28

Cheung P, Tanner KG, Cheung WL, Sassone-Corsi P, Denu JM, Allis CD (2000) Synergistic coupling of histone $\mathrm{H} 3$ phosphorylation and acetylation in response to epidermal growth factor stimulation. Mol. Cell 5:905-15

Chwang WB, Arthur JS, Schumacher A, Sweatt JD (2007) The nuclear kinase mitogen- and stress-activated protein kinase 1 regulates hippocampal chromatin remodeling in memory formation. J. Neurosci. 27:12732-42

Clayton AL, Rose S, Barratt MJ, Mahadevan LC (2000) Phosphoacetylation of histone H3 on c-fos- and c-jun-associated nucleosomes upon gene activation. EMBO J. 19:3714-26

Cordero MI, Sandi C (1998) A role for brain glucocorticoid receptors in contextual fear conditioning: dependence upon training intensity. Brain Res. 786:11-7

Cosgrove MS, Patel A (2010) Mixed lineage leukemia: a structure-function perspective of the MLL1 protein. FEBS J. 277:1832-42

Crosio C, Heitz E, Allis CD, Borrelli E, Sassone-Corsi P (2003) Chromatin remodeling and neuronal response: multiple signaling pathways induce specific histone $\mathrm{H} 3$ modifications and early gene expression in hippocampal neurons. J. Cell Sci. 116:4905-14

Davis M, Astrachan DI (1978) Conditioned fear and startle magnitude: effects of different footshock or backshock intensities used in training. J. Exp. Psychol. Anim. Behav. Process. 4:95-103

Dayas CV, Buller KM, Crane JW, Xu Y, Day TA (2001) Stressor categorization: acute physical and psychological stressors elicit distinctive recruitment patterns in the amygdala and in medullary noradrenergic cell groups. Eur. J. Neurosci. 14:1143-52

De Kloet ER, De Kock S, Schild V, Veldhuis HD (1988) Antiglucocorticoid RU 38486 attenuates retention of a behaviour and disinhibits the hypothalamic-pituitary adrenal axis at different brain sites. Neuroendocrinology 47:109-15

De Kloet ER, Reul JMHM (1987) Feedback action and tonic influence of corticosteroids on brain function: a concept arising from the heterogeneity of brain receptor systems.

Psychoneuroendocrinology 12:83-105

De Kloet ER, Joëls M, Holsboer F (2005) Stress and the brain: from adaptation to disease. Nat. Rev. Neurosci. 6:463-75

De Pablo JM, Parra A, Segovia S, Guillamón A (1989) Learned immobility explains the behavior of rats in the forced swimming test. Physiol. \& Behav. 46:229-37 
De Quervain DJ-F, Aerni A, Schelling G, Roozendaal B (2009) Glucocorticoids and the regulation of memory in health and disease. Front. Neuroendocrinol. 30:358-70

Derecki NC, Cardani AN, Yang CH, Quinnies KM, Crihfield A, Lynch KR, Kipnis J (2010) Regulation of learning and memory by meningeal immunity: a key role for IL-4. J. Exp. Med. 207:1067-80

Drobic B, Pérez-Cadahía B, Yu J, Kung SK-P, Davie JR (2010) Promoter chromatin remodeling of immediate-early genes is mediated through $\mathrm{H} 3$ phosphorylation at either serine 28 or 10 by the MSK1 multi-protein complex. Nucleic Acids Res. 38:3196-208

Elenkov IJ, Chrousos GP (2002) Stress hormones, proinflammatory and antiinflammatory cytokines, and autoimmunity. Ann. N. Y. Acad. Sci. 966:290-303

Evans AK, Lowry CA (2007) Pharmacology of the beta-carboline FG-7,142, a partial inverse agonist at the benzodiazepine allosteric site of the GABA A receptor: neurochemical, neurophysiological, and behavioral effects. CNS Drug Rev. 13:475-501

Green AR, Vincent ND (1987) The effect of repeated electroconvulsive shock on GABA synthesis and release in regions of rat brain. Br. J. Pharmacol. 92:19-24

Gutierrez-Mecinas M, Collins A, Qian X, Hesketh S, Reul JM (2009) Forced swimming evoked histone $\mathrm{H} 3$ phospho-acetylation and c-Fos induction in dentate gyrus granule neurons involves ERK1/2-mediated MSK1 and Elk-1 phosphorylation. Society of Neuroscience Abstracts Available at: http://www.abstractsonline.com/Plan/SSResults.aspx [Accessed November 29, 2010].

Hauge C, Frödin M (2006) RSK and MSK in MAP kinase signalling. J. Cell Sci. 119:3021-3

Heesen C, Gold SM, Huitinga I, Reul JMHM (2007) Stress and hypothalamic-pituitaryadrenal axis function in experimental autoimmune encephalomyelitis and multiple sclerosis a review. Psychoneuroendocrinology 32:604-18

Heim C, Newport DJ, Mletzko T, Miller AH, Nemeroff CB (2008) The link between childhood trauma and depression: insights from HPA axis studies in humans.

Psychoneuroendocrinology 33:693-710

Herdegen T, Leah JD (1998) Inducible and constitutive transcription factors in the mammalian nervous system: control of gene expression by Jun, Fos and Krox, and CREB/ATF proteins. Brain Res. Brain Res. Rev. 28:370-490

Herman JP, Figueiredo H, Mueller NK, Ulrich-Lai Y, Ostrander MM, Choi DC, Cullinan WE (2003) Central mechanisms of stress integration: hierarchical circuitry controlling hypothalamo-pituitary-adrenocortical responsiveness. Front. Neuroendocrinol. 24:151-180

Hoffman GE, Smith MS, Verbalis JG (1993) c-Fos and related immediate early gene products as markers of activity in neuroendocrine systems. Front. Neuroendocrinol. 14:173213 
Hyllus D, Stein C, Schnabel K, Schiltz E, Imhof A, Dou Y, Hsieh J, Bauer U-M (2007) PRMT6-mediated methylation of R2 in histone H3 antagonizes H3 K4 trimethylation. Genes \& Dev. 21:3369-80

Illingworth RS, Bird AP (2009) CpG islands-- $\square$ a raugh guide'. FEBS lett. 583:1713-20

Jefferys D, Copolov D, Irby D, Funder J (1983) Behavioural effect of adrenalectomy: reversal by glucocorticoids or [D-Ala2,Met5]enkephalinamide. Eur. J. Pharmacol. 92:99-103

Kalueff A, Nutt DJ (1996) Role of GABA in memory and anxiety. Depress. Anxiety 4:10010

Ko M, Huang Y, Jankowska AM, Pape UJ, Tahiliani M, Bandukwala HS, An J, Lamperti ED, Koh KP, Ganetzky R, Liu XS, Aravind L, Agarwal S, Maciejewski JP, Rao A (2010) Impaired hydroxylation of 5-methylcytosine in myeloid cancers with mutant TET2. Nature 468:839-43

Korte SM (2001) Corticosteroids in relation to fear, anxiety and psychopathology. Neurosci. Biobehav. Rev. 25:117-42

Kouzarides T (2007) Chromatin modifications and their function. Cell 128:693-705

Kraus J, Lehmann L, Börner C, Höllt V (2010) Epigenetic mechanisms involved in the induction of the mu opioid receptor gene in Jurkat T cells in response to interleukin-4. Mol. Immunol. 48:257-63

Labeur MS, Arzt E, Wiegers GJ, Holsboer F, Reul JMHM (1995) Long-term intracerebroventricular corticotropin-releasing hormone administration induces distinct changes in rat splenocyte activation and cytokine expression. Endocrinology 136:2678-88

Li Q-J, Yang S-H, Maeda Y, Sladek FM, Sharrocks AD, Martins-Green M (2003) MAP kinase phosphorylation-dependent activation of Elk-1 leads to activation of the co-activator p300. EMBO J. 22:281-91

Liberman AC, Druker J, Perone MJ, Arzt E (2007) Glucocorticoids in the regulation of transcription factors that control cytokine synthesis. Cytokine Growth Factor Rev. 18:45-56

Liberzon I, Krstov M, Young EA (1997) Stress-restress: effects on ACTH and fast feedback. Psychoneuroendocrinology 22:443-53

Linthorst AC, Flachskamm C, Holsboer F, Reul JMHM (1994) Local administration of recombinant human interleukin-1 beta in the rat hippocampus increases serotonergic neurotransmission, hypothalamic-pituitary-adrenocortical axis activity, and body temperature. Endocrinology 135:520-32

Linthorst AC, Flachskamm C, Holsboer F, Reul JMHM (1995)(a) Intraperitoneal administration of bacterial endotoxin enhances noradrenergic neurotransmission in the rat preoptic area: relationship with body temperature and hypothalamic--pituitary--adrenocortical axis activity. Eur. J. Neurosci. 7:2418-30 
Linthorst AC, Flachskamm C, Holsboer F, Reul JMHM (1996) Activation of serotonergic and noradrenergic neurotransmission in the rat hippocampus after peripheral administration of bacterial endotoxin: involvement of the cyclo-oxygenase pathway. Neuroscience 72:98997

Linthorst AC, Flachskamm C, Müller-Preuss P, Holsboer F, Reul JMHM (1995)(b) Effect of bacterial endotoxin and interleukin-1 beta on hippocampal serotonergic neurotransmission, behavioral activity, and free corticosterone levels: an in vivo microdialysis study. J. Neurosci. $15: 2920-34$

Linthorst a C, Karanth S, Barden N, Holsboer F, Reul JMHM (1999) Impaired glucocorticoid receptor function evolves in aberrant physiological responses to bacterial endotoxin. Eur. J. Neurosci. 11:178-86

Linthorst ACE, Flachskamm C, Reul JMHM (2008) Water temperature determines neurochemical and behavioural responses to forced swim stress: an in vivo microdialysis and biotelemetry study in rats. Stress 11:88-100

Linthorst ACE, Reul JMHM (2008) Stress and the brain: solving the puzzle using microdialysis. Pharmacol. Biochem. Behav. 90:163-73

Linthorst ACE, Peñalva RG, Flachskamm C, Holsboer F, Reul JMHM (2002) Forced swim stress activates rat hippocampal serotonergic neurotransmission involving a corticotropinreleasing hormone receptor-dependent mechanism. Eur. J. Neurosci. 16:2441-52

Lucki I (1997) The forced swimming test as a model for core and component behavioral effects of antidepressant drugs. Behav. Pharmacol. 8:523-32

Mastronardi FG, Noor A, Wood DD, Paton T, Moscarello MA (2007) Peptidyl argininedeiminase $2 \mathrm{CpG}$ island in multiple sclerosis white matter is hypomethylated. $\mathrm{J}$. Neurosci. Res. 85:2006-16

Mathews HL, Janusek LW (2011) Epigenetics and psychoneuroimmunology: mechanisms and models. Brain, Behav., Immun. 25:25-39

McEwen BS (2000) The neurobiology of stress: from serendipity to clinical relevance. Brain Res. 886:172-189

McGowan PO, Sasaki A, D $\square$ Alessio AC, Dymov S, Labonté B, Szyf M, Turecki G, Meaney MJ (2009) Epigenetic regulation of the glucocorticoid receptor in human brain associates with childhood abuse. Nature Neurosci. 12:342-8

Morris RG, Garrud P, Rawlins JN, O Keefe J (1982) Place navigation impaired in rats with hippocampal lesions. Nature 297:681-3

Nair J, Singh Ajit S (2008) The role of the glutamatergic system in posttraumatic stress disorder. CNS Spec. 13:585-91

Nakayama J, Klar AJ, Grewal SI (2000) A chromodomain protein, Swi6, performs imprinting functions in fission yeast during mitosis and meiosis. Cell 101:307-17 
Nestler EJ, Hyman SE (2010) Animal models of neuropsychiatric disorders. Nature Neurosci. $13: 1161-9$

Ng SS, Yue WW, Oppermann U, Klose RJ (2009) Dynamic protein methylation in chromatin biology. Cell Mol. Life Sci. 66:407-22

Nolan Y, Maher FO, Martin DS, Clarke RM, Brady MT, Bolton AE, Mills KHG, Lynch M a (2005) Role of interleukin-4 in regulation of age-related inflammatory changes in the hippocampus. J. Biol. Chem. 280:9354-62

Nowak SJ, Corces VG (2000) Phosphorylation of histone H3 correlates with transcriptionally active loci. Genes \& Dev. 14:3003-13

Oitzl MS, Kloet ER de (1992) Selective corticosteroid antagonists modulate specific aspects of spatial orientation learning. Behav. Neurosci 106:62-71

Olton DS, Samuelson RJ (1976) Remembrance of places passed: Spatial memory in rats. J. Exp. Psychol. Anim. Behav. Process. 2:97-116

Pace TWW, Heim CM (2011) A short review on the psychoneuroimmunology of posttraumatic stress disorder: from risk factors to medical comorbidities. Brain, Behav., Immun. 25:6-13

Papadopoulos A, Chandramohan Y, Collins A, Droste SK, Nutt DJ, Reul JMHM (2010) GABAergic control of novelty stress-responsive epigenetic and gene expression mechanisms in the rat dentate gyrus. Eur. Neuropsychopharm.

Penn NW, Suwalski R, O $\square$ Riley C, Bojanowski K, Yura R (1972) The presence of 5 hydroxymethylcytosine in animal deoxyribonucleic acid. Biochem. J. 126:781-90

Porsolt RD, Le Pichon M, Jalfre M (1977) Depression: a new animal model sensitive to antidepressant treatments. Nature 266:730-2

Rescorla RA (1973) Effect of US habituation following conditioning. J. Comp. Physiol. Psychol. 82:137-43

Reul JMHM, Nutt DJ (2008) Glutamate and cortisol--a critical confluence in PTSD? J. Psychopharmacol. (London, U. K.) 22:469-72

Reul JMHM, Kloet ER de (1985) Two receptor systems for corticosterone in rat brain: microdistribution and differential occupation. Endocrinology 117:2505-11

Reul JMHM, Labeur MS, Wiegers GJ, Linthorst AC (1998) Altered neuroimmunoendocrine communication during a condition of chronically increased brain corticotropin-releasing hormone drive. Ann. N. Y. Acad. Sci. 840:444-55

Reul JMHM, Chandramohan Y (2007) Epigenetic mechanisms in stress-related memory formation. Psychoneuroendocrinology 32 Suppl 1:S21-5 
Reul JMHM, Hesketh SA, Collins A, Mecinas MG (2009) Epigenetic mechanisms in the dentate gyrus act as a molecular switch in hippocampus-associated memory formation. Epigenetics 4:434-9

Revest J-M, Di Blasi F, Kitchener P, Rougé-Pont F, Desmedt A, Turiault M, Tronche F, Piazza PV (2005) The MAPK pathway and Egr-1 mediate stress-related behavioral effects of glucocorticoids. Nature Neurosci. 8:664-72

Sandi C (2011) Glucocorticoids act on glutamatergic pathways to affect memory processes. Trends Neurosci. 34:165-176

Schaaf MJ, De Kloet ER, Vreugdenhil E (2000) Corticosterone effects on BDNF expression in the hippocampus. Implications for memory formation. Stress 3:201-8

Schmidt ED, Aguilera G, Binnekade R, Tilders FJH (2003) Single administration of interleukin-1 increased corticotropin releasing hormone and corticotropin releasing hormonereceptor mRNA in the hypothalamic paraventricular nucleus which paralleled long-lasting (weeks) sensitization to emotional stressors. Neuroscience 116:275-83

Schreiber SL, Bernstein BE (2002) Signaling network model of chromatin. Cell 111:771-8

Schöbitz B, Reul JMHM, Holsboer F (1994) The role of the hypothalamic-pituitaryadrenocortical system during inflammatory conditions. Crit. Rev. Neurobiol. 8:263-91

Soloaga A, Thomson S, Wiggin GR, Rampersaud N, Dyson MH, Hazzalin CA, Mahadevan LC, Arthur JSC (2003) MSK2 and MSK1 mediate the mitogen- and stress-induced phosphorylation of histone H3 and HMG-14. EMBO J. 22:2788-97

Stefferl A, Linington C, Holsboer F, Reul JMHM (1999) Susceptibility and resistance to experimental allergic encephalomyelitis: relationship with hypothalamic-pituitaryadrenocortical axis responsiveness in the rat. Endocrinology 140:4932-8

Stefferl A, Storch MK, Linington C, Stadelmann C, Lassmann H, Pohl T, Holsboer F, Tilders FJ, Reul JMHM (2001) Disease progression in chronic relapsing experimental allergic encephalomyelitis is associated with reduced inflammation-driven production of corticosterone. Endocrinology 142:3616-24

Sterzer P, Wiegers GJ, Reul JMHM (2004) Long-term in vivo administration of glucocorticoid hormones attenuates their capacity to accelerate in vitro proliferation of rat splenic T cells. Endocrinology 145:3630-8

Tahiliani M, Koh KP, Shen Y, Pastor WA, Bandukwala H, Brudno Y, Agarwal S, Iyer LM, Liu DR, Aravind L, Rao A (2009) Conversion of 5-methylcytosine to 5hydroxymethylcytosine in mammalian DNA by MLL partner TET1. Science 324:930-5

Takei S, Morinobu S, Yamamoto S, Fuchikami M, Matsumoto T, Yamawaki S (2010) Enhanced hippocampal BDNF/TrkB signaling in response to fear conditioning in an animal model of posttraumatic stress disorder. J. Psychiatr. Res.1-9 
Thomson S, Clayton AL, Hazzalin CA, Rose S, Barratt MJ, Mahadevan LC (1999)(a) The nucleosomal response associated with immediate-early gene induction is mediated via alternative MAP kinase cascades: MSK1 as a potential histone H3/HMG-14 kinase. EMBO J. 18:4779-93

Thomson S, Mahadevan LC, Clayton AL (1999)(b) MAP kinase-mediated signalling to nucleosomes and immediate-early gene induction. Semin. Cell. Dev. Biol. 10:205-14

Uddin M, Aiello AE, Wildman DE, Koenen KC, Pawelec G, Los Santos R de, Goldmann E, Galea S (2010) Epigenetic and immune function profiles associated with posttraumatic stress disorder. Proc. Natl. Acad. Sci. U. S. A. 107:9470-5

Valinluck V, Sowers LC (2007) Endogenous cytosine damage products alter the site selectivity of human DNA maintenance methyltransferase DNMT1. Cancer Res. 67:946-50

Vecsey CG, Hawk JD, Lattal KM, Stein JM, Fabian SA, Attner MA, Cabrera SM, McDonough CB, Brindle PK, Abel T, Wood MA (2007) Histone deacetylase inhibitors enhance memory and synaptic plasticity via CREB:CBP-dependent transcriptional activation. J. Neurosci. 27:6128-40

Veldhuis HD, De Kloet ER (1983) Antagonistic effects of aldosterone on corticosteronemediated changes in exploratory behavior of adrenalectomized rats. Horm. Behav. 17:225-32

Weaver ICG, Cervoni N, Champagne FA, D $\square$ Alessio AC, Sharma S, Seckl JR, Dymov S, Szyf M, Meaney MJ (2004) Epigenetic programming by maternal behavior. Nature Neurosci. $7: 847-54$

West AP (1990) Neurobehavioral studies of forced swimming: the role of learning and memory in the forced swim test. Prog. Neuropsychopharmacol. Biol. Psychiatry. 14:863-77

Wiegers GJ, Labeur MS, Stec IE, Klinkert WE, Holsboer F, Reul JMHM (1995)

Glucocorticoids accelerate anti-T cell receptor-induced T cell growth. J. Immunol. 155:1893902

Wiegers GJ, Reul JMHM (1998) Induction of cytokine receptors by glucocorticoids: functional and pathological significance. Trends Pharmacol. Sci. 19:317-21

Wiegers GJ, Stec IE, Klinkert WE, Linthorst AC, Reul JMHM (2001) Bidirectional effects of corticosterone on splenic T-cell activation: critical role of cell density and culture time.

Neuroendocrinology 73:139-48

Wiegers GJ, Stec IE, Klinkert WE, Reul JMHM (2000) Glucocorticoids regulate TCRinduced elevation of CD4: functional implications. J. Immunol. 164:6213-20

Wu SC, Zhang Y (2010) Active DNA demethylation: many roads lead to Rome. Nat. Rev. Mol. Cell. Biol. 11:607-20

Yamamoto S, Morinobu S, Takei S, Fuchikami M, Matsuki A, Yamawaki S, Liberzon I (2009) Single prolonged stress: toward an animal model of posttraumatic stress disorder. Depress. Anxiety 26:1110-7 
Yehuda R, Bierer LM (2009) The relevance of epigenetics to PTSD: Implications for the DSM-V. J. Trauma. Stress. 22:427-434

Yuen P, Tsitiridis A, Kam F, Jackman J, James D, Richardson M, Williams L, Oxford W, Piper J, Thomas F, Lightman S (2009) Emotional \& physical stress detection and classification using thermal imaging technique. 3rd International Conference on Imaging for Crime Detection and Prevention (ICDP 2009):P13-P13 Available at: http://link.aip.org/link/IEESEM/v2009/i2/pP13/s1\&Agg=doi [Accessed March 8, 2011].

Zhang H, Zhang X, Clark E, Mulcahey M, Huang S, Shi YG (2010) TET1 is a DNA-binding protein that modulates DNA methylation and gene transcription via hydroxylation of 5methylcytosine. Cell Res. 20:1390-3 


\section{Legend to Figure 1.}

\section{Scheme representing the role of the epigenome in physiological and behavioral}

responses. Cells communicate by a number of chemical messengers which act at different locations to elicit a biological response. Generally, signaling systems exist whereby extracellular primary messengers (growth factors, cytokines, hormones etc) act via receptors at the cell surface or are transported or diffuse across the plasma membrane to induce activation of secondary messengers and/or transcription factors within the cytoplasm. Activated secondary messengers can have biochemical effects in the cytoplasm and/or are translocated into the nucleus to act on nuclear transcription factors or influence the epigenome or genome directly. The epigenome is regarded as the complex of changes, occurring at the chromatin level, which alter the expression of genes without changing the coding sequence of the genome. Changing the level of gene products, as a result of activation of signaling cascades, influences cell function and affects both the physiology and the behavior of the organism. 


\section{Legend to Figure 2.}

\section{Concept on the requirement of orchestrated signaling and epigenetic mechanisms in the}

induction of c-Fos in dentate granule neurons after a psychological challenge. A. Under baseline conditions the $c$-fos gene in an inactive state possibly involving methylation of the gene promoter DNA. B. Psychological stress causes the secretion of glucocorticoid hormone which act via GRs and the release of glutamate which acts on NMDARs to cause a rise in intracellular $\mathrm{Ca}^{2+}$ levels in sparsely distributed dentate granule neurons. $\mathrm{Ca}^{2+}$ influx activates CAMKII and the ERK MAPK cascade. We recently discovered that GRs seem to act like scaffolds facilitating the activation (i.e. phosphorylation) of MSK1 and Elk-1 by phosphorylated ERK1/2 (pERK1/2; Gutierrez-Mecinas et al., submitted). pMSK1 phosphorylates S10 residues in histone $\mathrm{H} 3$ tails which evokes the opening of the chromatin. If the $c$-fos gene promoter is methylated de-methylation (by DNA de-methylases (DDMs)) will take place at this stage or earlier. CAMKII and MSK1 and possibly other kinases (e.g. protein kinase A (PKA)) will phosphorylate CREB. pElk-1 will bind to the Elk-1 binding site in the serum response element (SRE) and recruit and phosphorylate the HAT p300. pCREB and GRs may also recruit HATs. The recruited HATs will acetylate the histone tails (including $\mathrm{H} 3 \mathrm{~S} 10 \mathrm{p}$ rendering it into $\mathrm{H} 3 \mathrm{~S} 10 \mathrm{p}-\mathrm{K} 14 \mathrm{ac}$ ) and thereby stabilize the open chromatin configuration. This may also involve H3K4 methylation by HMTs but their activation/recruitment mechanisms are still unknown. Dimerized pCREB can now access the CRE within the $c$-fos promoter and transactivate gene transcription. The c-Fos response is a transient response as, over time, glucocorticoid hormones and glutamate diminish, $\mathrm{Ca}^{2+}$ levels plummet, protein phosphatase and HDAC activities rise and ultimately the $c$-fos gene will be inactivated, possibly involving DNA methylation of the gene promoter. 
Table 1. Behavioral tests commonly used to investigate responses to stress or learning and memory paradigms.

\begin{tabular}{|c|c|c|c|c|}
\hline Behavioral test & General conditions & $\begin{array}{l}\text { Adaptive } \\
\text { behavior }\end{array}$ & $\begin{array}{l}\text { Reward (if } \\
\text { applicable) }\end{array}$ & References \\
\hline Novel environment & $\begin{array}{l}\text { Subjects are transferred to } \\
\text { a new environment } \\
\text { (usually for } 30 \mathrm{~min} \text { ) and } \\
\text { their behavior recorded. }\end{array}$ & $\begin{array}{l}\text { Switch from } \\
\text { exploratory } \\
\text { to normal } \\
\text { behavior }\end{array}$ & $\begin{array}{l}\text { Identifying } \\
\text { there is no } \\
\text { threat }\end{array}$ & $\begin{array}{c}\text { (Bassett et al., } \\
\text { 1973) }\end{array}$ \\
\hline Radial maze & $\begin{array}{l}\text { 8-arm maze which tests } \\
\text { subjects memory by } \\
\text { forcing them to make } \\
\text { decisions about which arm } \\
\text { to explore. }\end{array}$ & $\begin{array}{l}\text { Finding } \\
\text { food source }\end{array}$ & Food & $\begin{array}{l}\text { (Olton and } \\
\text { Samuelson, } \\
\text { 1976) }\end{array}$ \\
\hline Morris water maze & $\begin{array}{l}\text { Subjects are trained } \\
\text { (successive trials over } \\
\text { consecutive days) to find } \\
\text { an underwater platform } \\
\text { and then the platform is } \\
\text { removed to test their } \\
\text { memory of its location. }\end{array}$ & $\begin{array}{l}\text { Finding the } \\
\text { platform }\end{array}$ & $\begin{array}{c}\text { Escape from } \\
\text { water }\end{array}$ & $\begin{array}{c}\text { (Morris et al., } \\
\text { 1982) }\end{array}$ \\
\hline Forced swim test & $\begin{array}{l}\text { Subjects are placed in are } \\
\text { large beaker of water from } \\
\text { which they cannot touch } \\
\text { the bottom or escape and } \\
\text { behavior monitored }\end{array}$ & Floating & $\begin{array}{c}\text { Conservation } \\
\text { of energy }\end{array}$ & $\begin{array}{l}\text { (Porsolt et al., } \\
\text { 1977 ; De } \\
\text { Pablo et al., } \\
\text { 1989; West, } \\
\text { 1990; Korte, }\end{array}$ \\
\hline
\end{tabular}




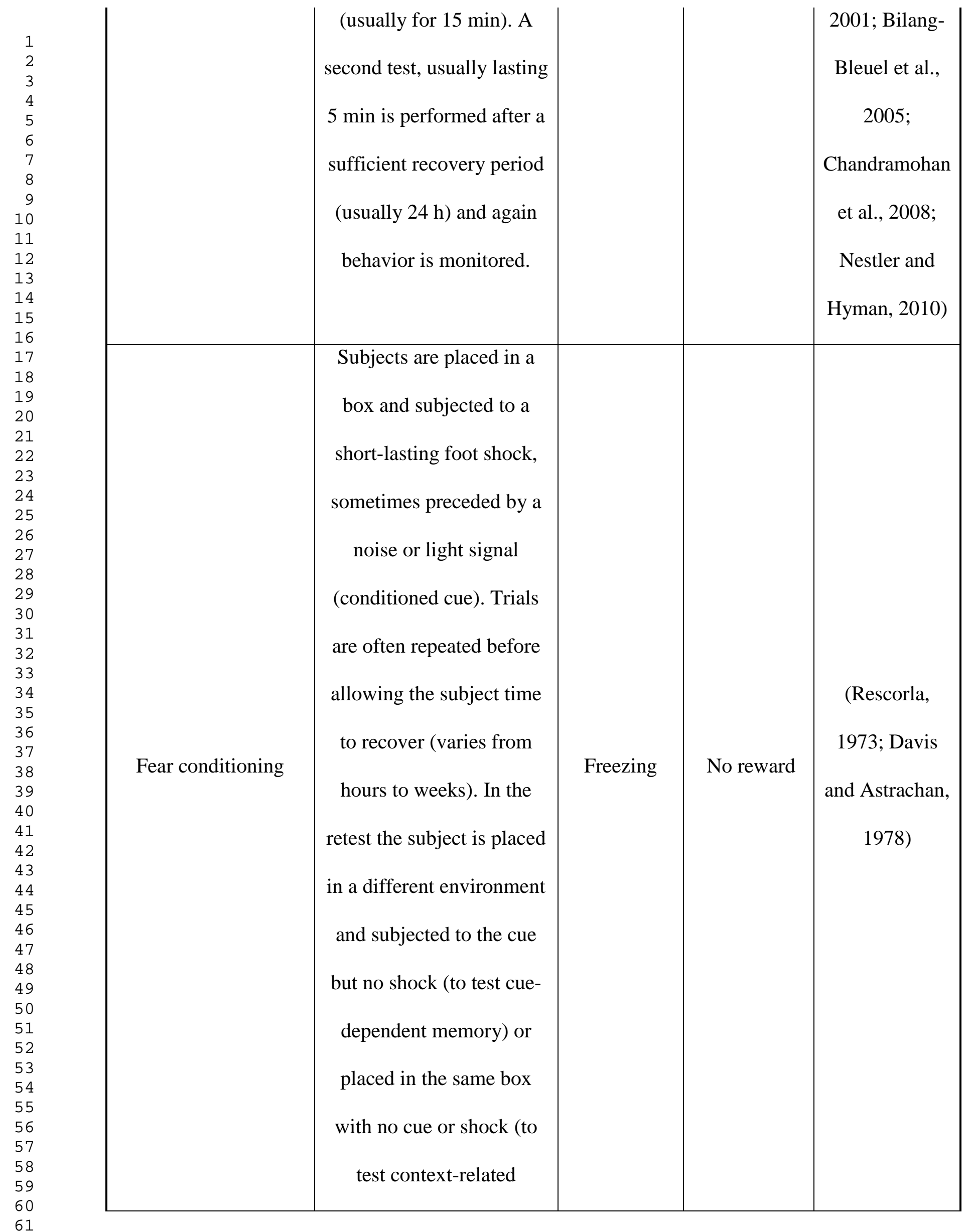




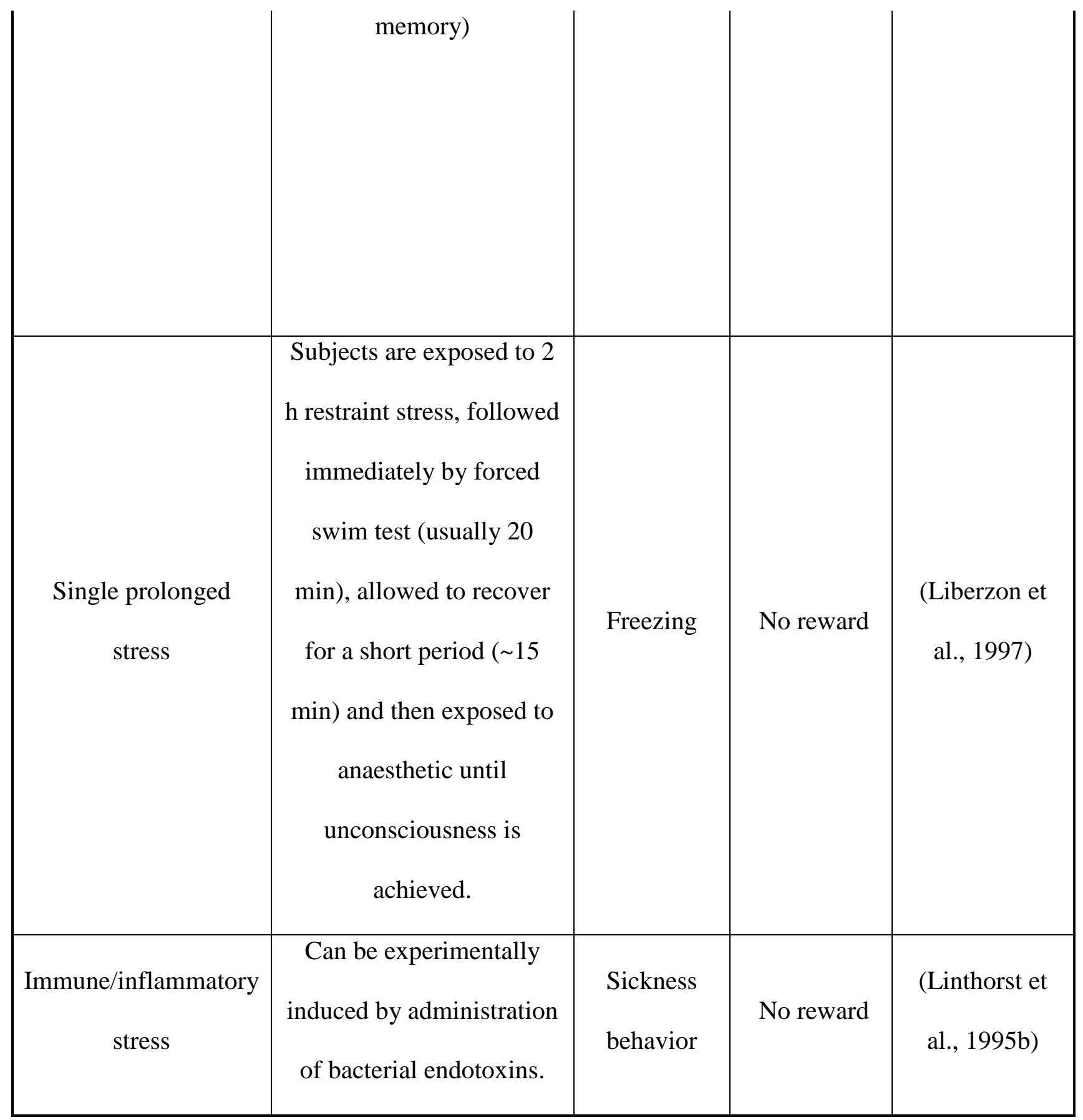

a Please note, this interpretation of the immobility response during forced swim retest differs from our own. 


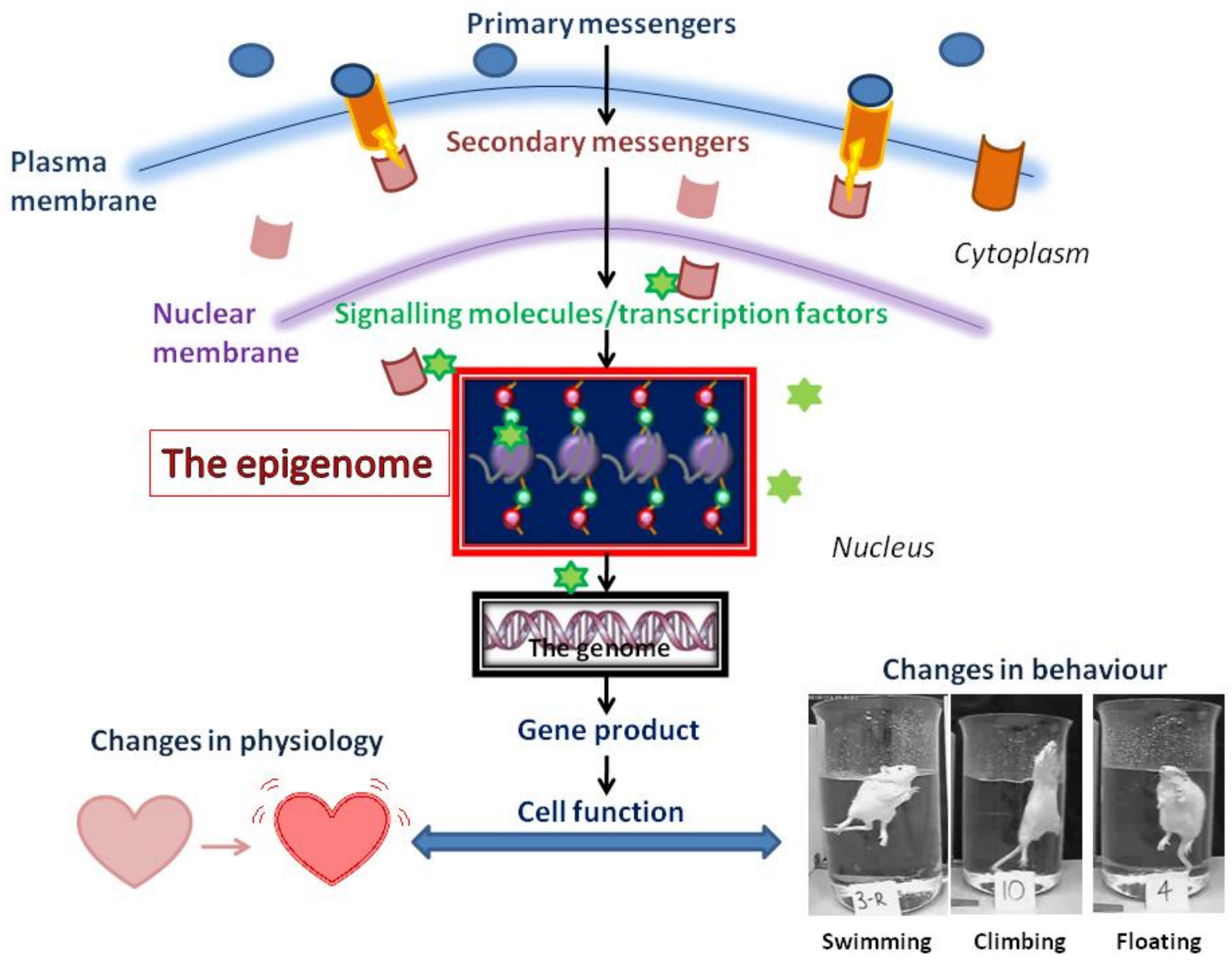


A. Baseline conditions
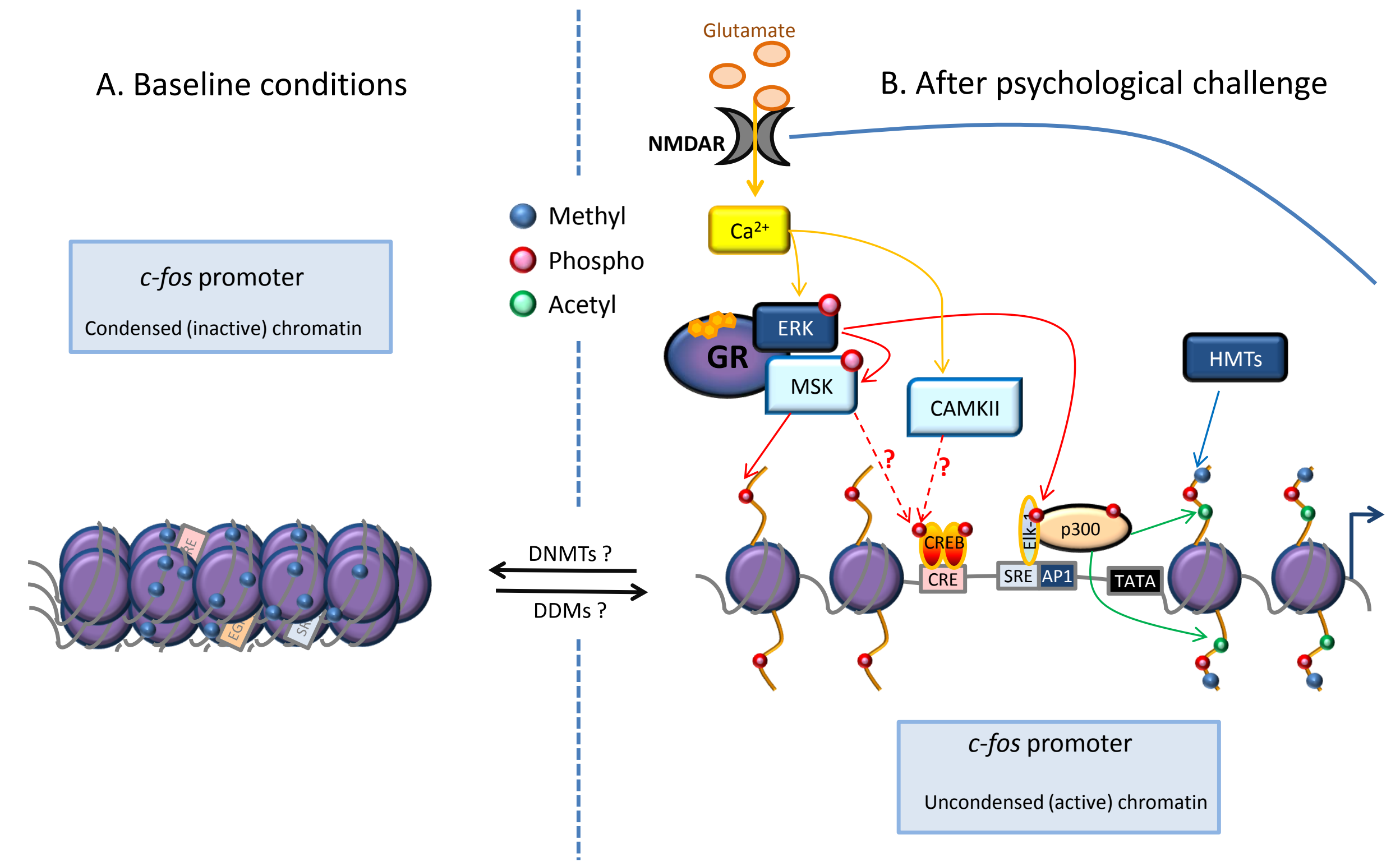